\title{
STUDY OF THE USE OF A MICRO HYDRO IN KNOCKDOWN CONTAINER COMPLETED WITH A CYLINDRICAL FORM HOUSING OF FRANCIS HYDRAULIC TURBINE TO SUPPORT THE DEVELOPMENT PROGRAM OF ENERGY SELF- SUSTAINABILITY FOR REMOTE AND ISOLATED AREAS IN INDONESIA
}

\author{
Samsul Kamal, Prajitno, Janu Pardadi \\ Mechanical and Industrial Engineering, Engineering Faculty, Universitas Gadjah Mada \\ Jl. Grafika No. 2 Kampus UGM, Yogyakarta, INDONESIA, 55281 \\ samsulugm@yahoo.com;samsul@ugm.ac.id
}

\begin{abstract}
With an intention to reduce the consumption of energy from fossil fuels and the $\mathrm{CO}_{2}$ emission in relation with the climate change solution, Indonesian Government has targeted that the role of the New and Renewable Energy (NRE) resources reaches at least $23 \%$, or about $27 \mathrm{GW}$, in 2025 and it is expected to increase to the extent of about $134 \mathrm{GW}$ in 2050 within the scenario of mixed energy supply. Geographically Indonesia has many remote and isolated areas with lack of appropriate infrastructure supports. But in the most of the areas, huge potential of new and renewable energy are available such as hydro energy is about $75 \mathrm{GW}$, biomass energy is about $32 \mathrm{GW}$ and bio fuel is about $32 \mathrm{GW}$. The total utilization of the energy from small hydro energy up to this year for example is only about $300 \mathrm{MW}$. The significant obstacle in optimizing the utilization of small hydro energy in the areas is mainly on the infrastructure conditions and the local manufacture capabilities. Difficulties in mobilization of experts, skill worker, parts and constructions material result in very time consuming and costly for site construction.

In this research a hydro turbine built in knock down container completed with a Francis turbine in cylindrical form housing is proposed and reported its performance on implementation. The hydro in a knock down container concept comes from the idea to manufacture hydro power solutions in a knock down container, readymade to be transported to installation sites. It can be easily manufactured in a quality controlled and cost effective environment, transported and installed in remote areas, to operate and maintain with minimal amount of equipment.

It shows that the implementation of the unit in a remote area has reduced the total site construction time by $1 / 3$ compared to the predicted one with conventional unit. The performance of the Francis turbine with cylindrical form housing has shown comparable with the conventional one which has volute form housing. The superiority was even more pronounced by introducing a deflection insert in its input flow channel. The insertion was capable to create more distributed flow into the runner. Efficiency of the turbine up to $80 \%$ was performed in this
\end{abstract}


research. Local manufacture for turbine usually use many craft work and welding to built a volute form housing for the Francis turbine. The cylindrical form housing here has also proven significantly in reducing the time and price for the turbine manufacturing process.

Keywords : Micro hydro, Francis turbine, container, isolated area.

\section{INTRODUCTION}

Indonesia is a large island country with around 17,000 islands spread over almost two million square kilometers, creating many remote areas. Most of the remote areas have minimum condition of utilities such as energy and also lack of adequate infrastructure such as roads. All of those conditions resulting the lack of economic development for most of the areas. In general the remote areas are very low dense population thus creating long distances between each hauses. This situation is also bring difficulties for government to construct a unified system of power generation to supply the need of energy on the scheme of nationwide scale [10]. The condition is now become even more uneasy and more expensive due to the decrease on the main national source of conventional sources of energy such as oil. It is fortunate, however, that the most of the remote areas have many type of renewable energy such as biomass, solar as well as hydro power potencies from small scale up to large scale. It is predicted that the potency of small hydro power in Indonesia is around $761 \mathrm{MW}$, but the utilization of the small hydro is only about $218 \mathrm{MW}$ or just around $28 \%$ and the rate of the utilization process is also said some how to be very slow [9]. This situation does not support the government commitment to reduce GHG emission up to $20 \%$ by 2020 [2]. There are many causes can be noticed for this situation for example due to the lack of infrastructure such as access road to the location where the hydro potential is identified, the capability of local workshop as well as local craftsman in supplying some mechanical parts of the turbine and in some civil works activities. All of these are actually problems which are generally encountered in the development of micro hydro power [5]. The hydro in a knock down container concept, as shown in Fig. 1, comes from the idea to manufacture hydro power solutions in a knock down container, readymade to be transported to installation sites. It can be easily manufactured in a quality controlled and cost effective environment, transported and installed in remote areas, to operate and maintain with minimal amount of equipment. 

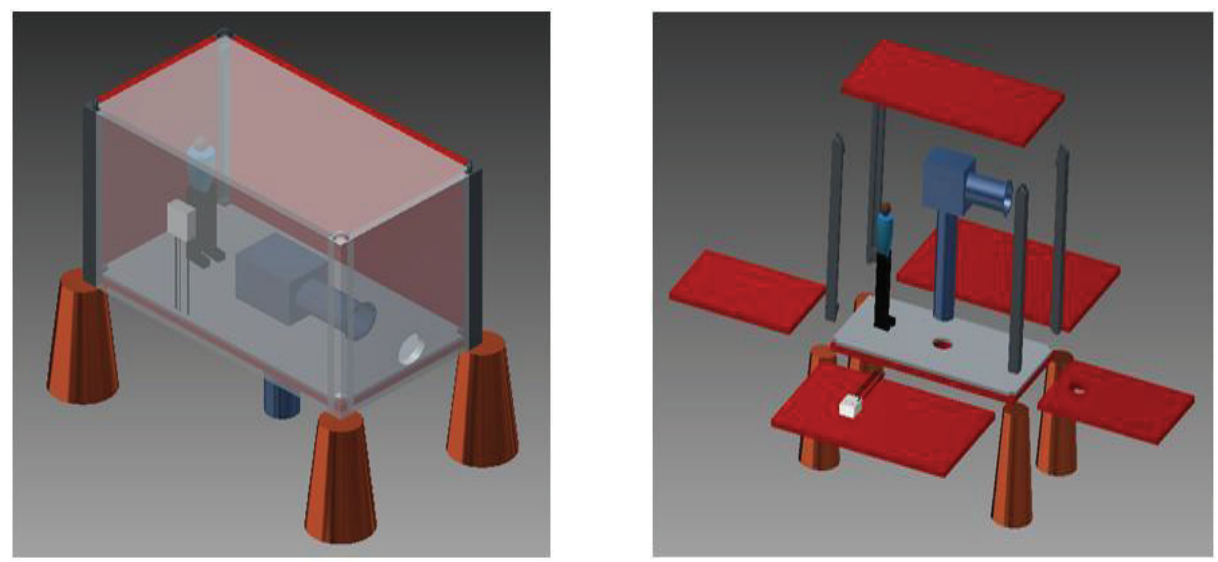

Figure 1. The concept of hydro in a knock down container.

For mechanical parts, there are two important parts in turbine that are runner and casing. For the runner, local foundry industries in developed part area of Indonesia such as in Java already have capability in producing runner turbine for Francis turbine. For the casing, however, the manufacturing process for the casing is still needed to be improved. They only manufacture a scrolled casing shape type which need longer time and work to be involved that cause this to be an expensive manufacturing process [1].

a.

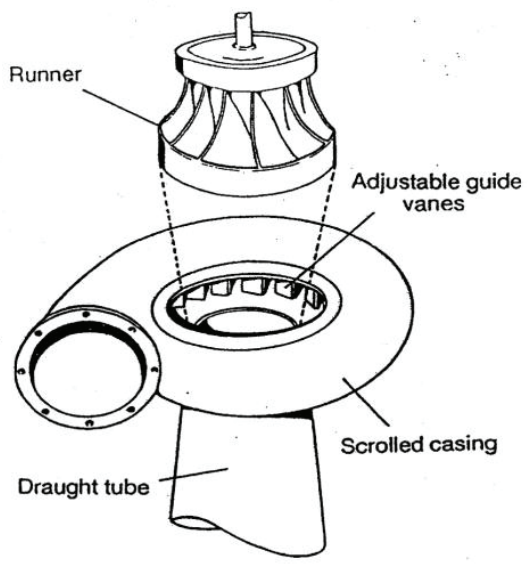

b.

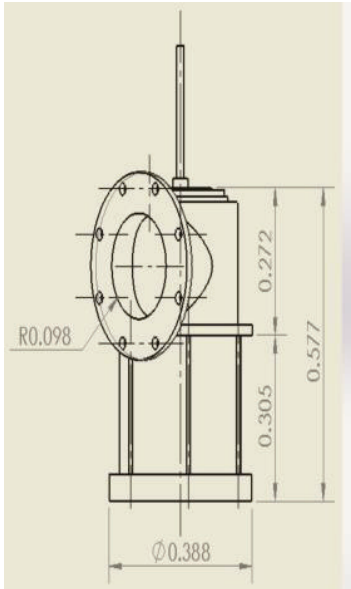

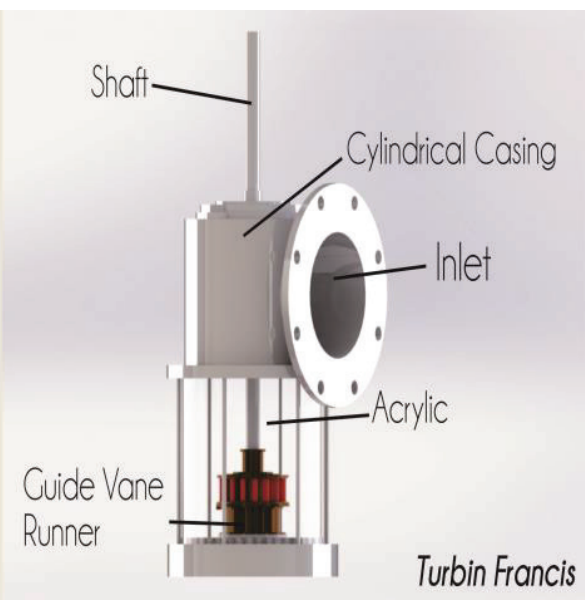

Figure 2. The scrolled (a) and cylindrical (b) casing for Francis turbine A cylindrical casing shape is proposed here. This casing consists two cylindrical pipes, large and small, joined together by welding. The larger pipe is used as casing where the smaller one is functioned as the inlet port. The inlet pipe port is welded eccentrically to the casing pipe to produce swirl. The construction is shown 
in Fig. 2. For the reason of experimental uses, an acrylic glass wall is fitted in the pipe casing to examine flow patterns during the experimental.

\section{MATERIAL AND METHODS}
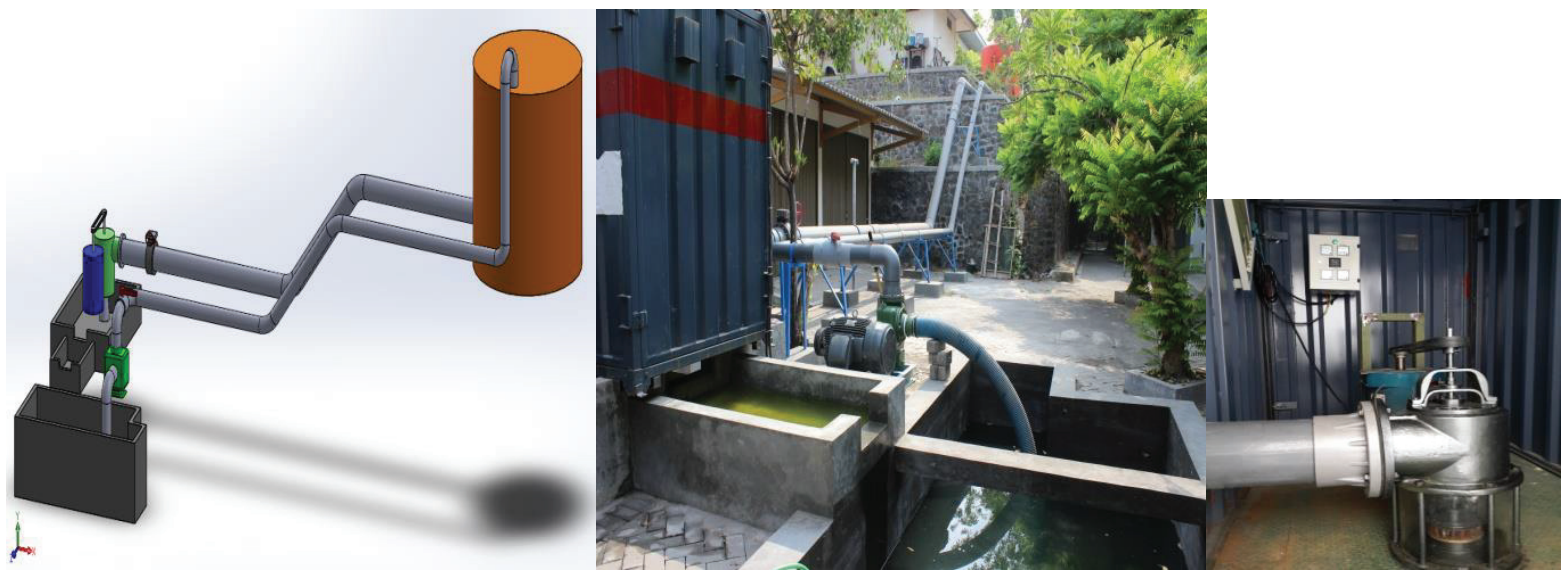

Figure 3. The test facility for the hydro in a container unit.

The micro hydro in knockdown container test facility has been developed in Mechanical and Industrial Engineering, Universitas Gadjah Mada. The test facility system is shown in Fig. 3. It uses an installation of high head water supply tank which is supplied by a pump. The turbine supply pipe (penstock) is constructed with adequate long and straight pipe to facilitate the pressure tank in the system to maintain flow steadiness. The turbine discharge directly into the sump which is completed with baffles to necessary prevent air from being drawn into the pump. Main instruments were installed in the facility, they are a stage marker for head measurement, an orifice plate and notches with weir for flow measurement, a mechanical tachometer for speed measurement and a torque meter and brake for torque measurement. Standard laboratory calibrations were used prior to the installation for the main instruments with acceptable accuracy. Test record sheets have been used where all experimental results are easily tabulated. The performance analysis follow the work of $[6,7]$. The recorded data consists : Valve setting (\%), total brake load (kg), speed (rpm), output power (W), head (m) and flow rate $\left(\mathrm{m}^{3} / \mathrm{sec}\right)$. The test was carried out for the two type of the turbine ; Francis with the scroll casing and Francis with the cylindrical casing. Valve setting in this test was varied from $100 \%$ (fully open) to $50 \%$ with decrement of $10 \%$. From the 
recorded data, they were then converted into turbine performance parameters for the following quantities to be determined ; output power $P o$ (Watts), input power $P i$ (Watts), efficiency $\eta$, specific speed $N s$ ( $\mathrm{rpm} . \mathrm{kW}^{1 / 2} \cdot \mathrm{m}^{-5 / 4}$ ), speed coefficient $C_{w}$ (rads), flow coefficient $C_{Q}$ and specific speed coefficient $C_{w s}$ (rads).

Error analysis was performed for variables involved. The most significant errors were found in the flow rate but overall accuracy achieved in this test is about $3 \%$.

A modification to improve the efficiency of the cylindrical casing Francis turbine was also examined by introducing an insertion profile, namely insertion profiles $\mathrm{A}$ and $\mathrm{B}$, which was rotationally placed in the inlet port of the turbine to modify the inlet flow to the guide vane as shown in Fig. 7 which was inspired by the work of [8]. A computer simulation was also provided to examine the dynamic performance of the flow in the turbine due to the insertion which follow the work of [3] and [6].
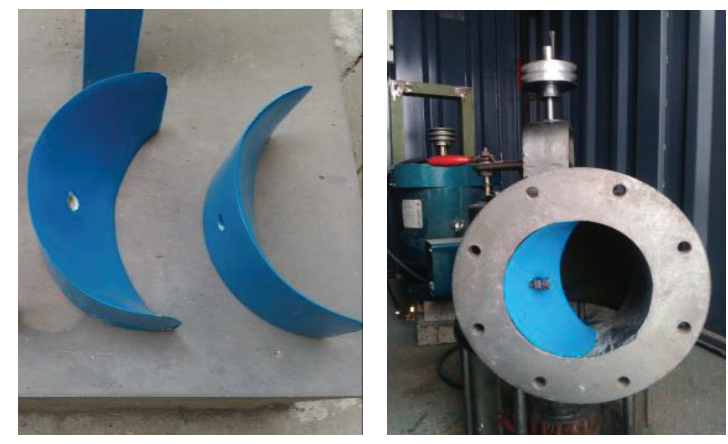

Figure 4. The insertion profile A and B and the inlet port in where the profiles are fitted

The different between the insertion A and B is on the angle of the slope made by the surface of the insertion to the surface of the inlet port which are expected to modify the swirl velocity vector. 


\section{PERFORMANCE AND EVALUATION}

The results of the measurement and the calculations are plotted into some different correlations which represent the performance indicators, that are efficiency $\eta$ versus speed coefficient $C_{w}$, flow coefficient $C_{Q}$ versus speed coefficient $C_{w}$ and efficiency $\eta$ versus specific speed coefficient $C_{w s}$.

First, the effect of insertion was examined. Figure 5 shows the effect of the insertion $\mathrm{A}$ and $\mathrm{B}$ to the bare inlet port (no insertion) for the same valve setting $100 \%$ (fully opened) to the turbine performance. Variations of the valve setting were also fully examined (from $100 \%$ to $50 \%$ with percentages decrement) but the results are not shown here. All the results has the same trend that the A insertion shows the best effect. It seems that the insertion will affect the whirl velocity component of the fluid flows to the guide vane, as expected, and it finally strikes to the runner. This was also noticed by [8]. This phenomena can also be indicated by the simulation results as shown in Figures 6.a and 6.b which compare the flow in the scrolled casing (6.a) and in the cylindrical casing (6.b) of Francis turbine for three different conditions that are no insertion, $\mathrm{A}$ insertion and $\mathrm{B}$ insertion. The $\mathrm{B}$ insertion on cylindrical casing results a resemble stream line flow with the scrolled casing. The vortex flows will smoothly developed around the guide vane producing no disturbances to the flow through the guide vane. This means that performance of the cylindrical casing turbine with B type insertion is comparable with the one with scrolled casing but the first has gain on reducing the complexities of the manufacturing process.

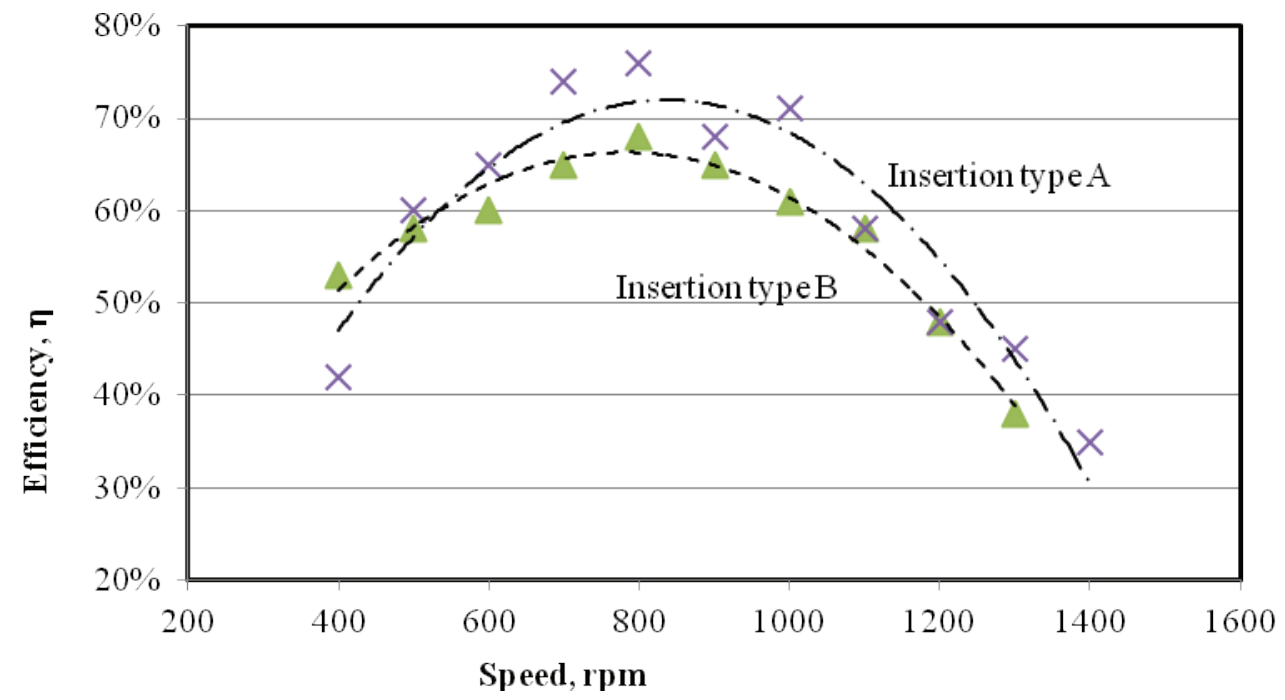

Figure 5. The effect of insertion type on the performance of the turbine 


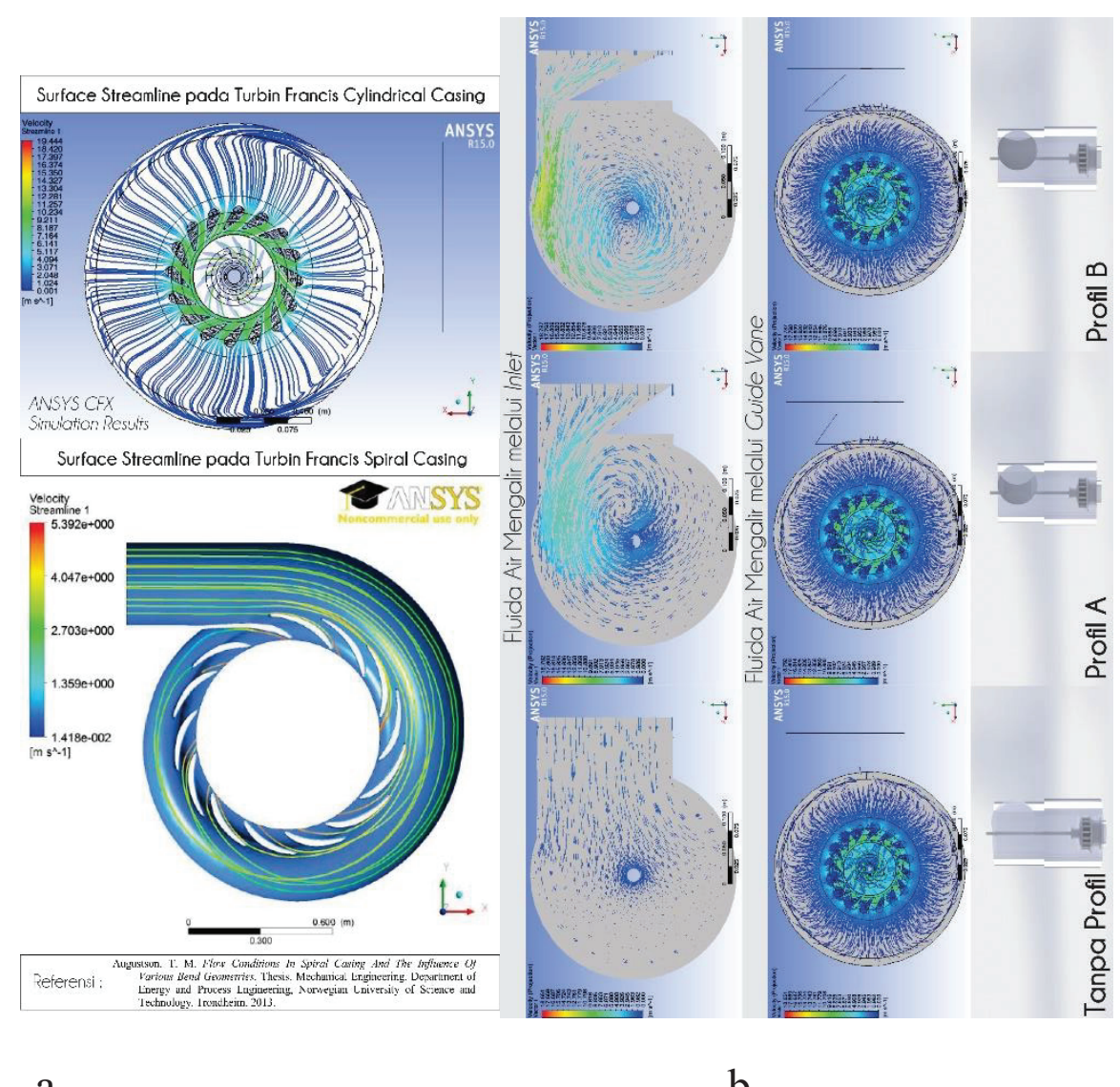

a

b

Figure 6. a. Surface streamline configuration of water flow inside the cylindrical casing and the scrolled (spiral) casing.

b. The effect of profile insertion on the inlet port to modify the flow distribution in the guide vanes in the cylindrical casing of Francis turbine.

Figure 7.a and Figure 7.b are used to explore further the performance of the cylindrical casing turbine with B type insertion, relating the efficiency $\eta$ and the specific speed, $\mathrm{C}_{\mathrm{ws}}$, for variation of valve settings $50 \%, 70 \%, 90 \%$ and $100 \%$. The best efficiency for this turbine is occurred at the valve setting of $100 \%$ and it goes up about $75 \%$. 


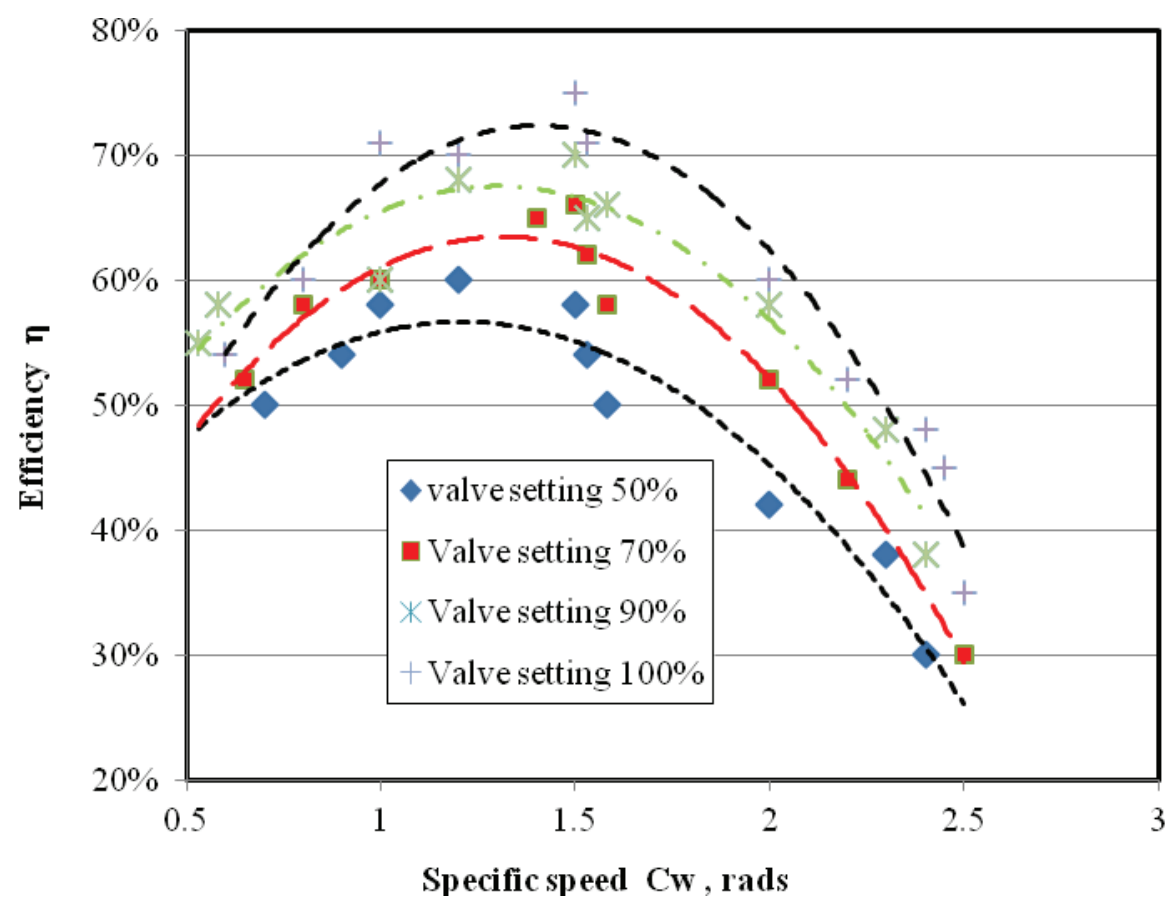

a

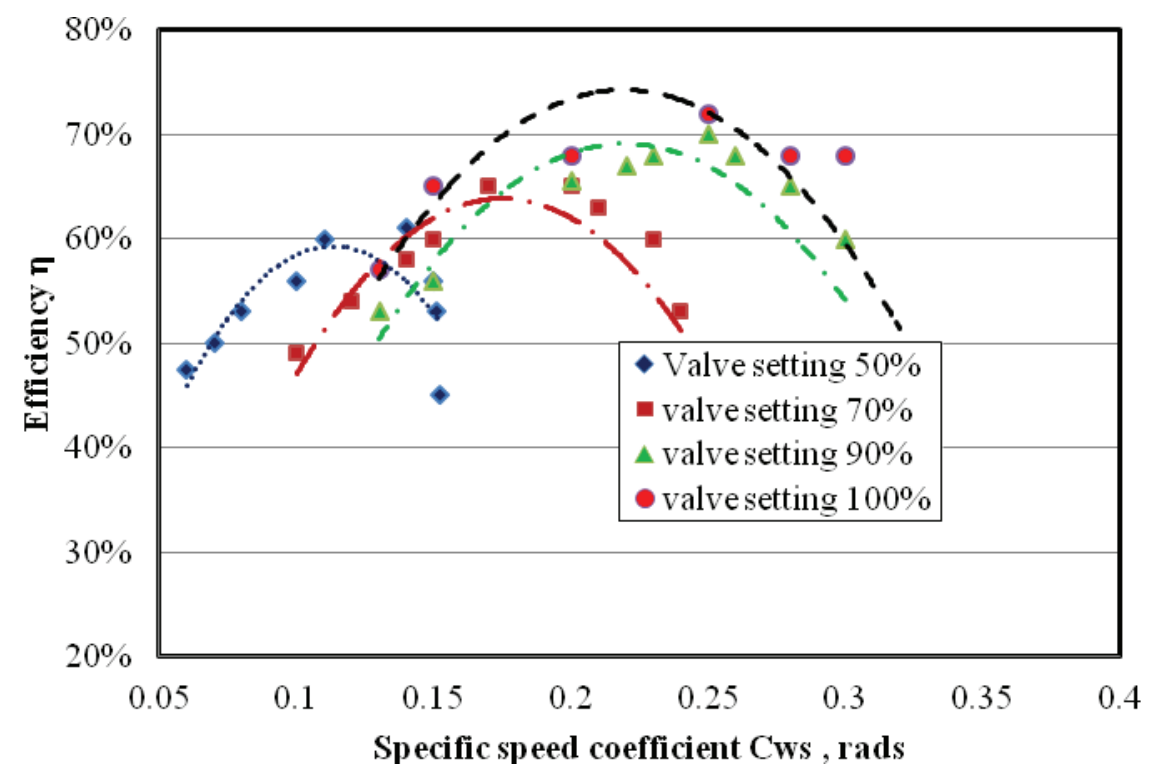

Figure 7. a. The performance of the turbine plotted against the specific speed with insertion type A.

b. The performance of the turbine plotted against the specific speed coefficient with insertion type A. 
The performance of the cylindrical casing turbine here is dictated significantly by the design of insertion. The best type of the insertion, that is A type, performed very well for the variation of the valve setting.

Time for site construction was investigated by installing the knock down container unit in a place near by an existing micro hydro of a similar size unit which was already built by using conventional civil work method. The existing, greatly, has an adequate data of the construction. Finally the man hour used for the site construction of the two are then compared. Result shows that the total man hour can be reduced up to about $1 / 3$. This result may also be used to predict the man hour needed for other location when the micro hydro in knockdown container is used although it must be also considered as well the level of the infrastructure difficulties in every specific location.

\section{CONCLUSION}

1. With a proper and specific design of the insertion, the performance of a cylindrical casing turbine could be more better than that of a scrolled casing turbine.

2. Cylindrical casing turbine could reduce the time and the difficulties in manufacturing process compared to the conventional type of casing that is scrolled type casing.

3. Micro hydro in a knockdown container completed with cylindrical casing turbine can significantly reduced the overall time for construction especially in an isolated area with lack of supporting adequate infrastructure. 


\section{REFERENCES}

[1] Adam Harvey, Andy Brown, Priyantha Hettiarachi and Allen Inversin (1993), Micro Hydro Design Manual, Intermediate Technology Publications, London.

[2] DEN , National Energy Council, (2015), National Energy Management, Jakarta Indonesia April 2015.

[3] Gohil, P. P., \& Saini, R. P. (2014). CFD: Numerical Analysis and Performance Prediction in Fancis Turbine. IEEE, 94-97.

[4] Jain, S., Saini, R. P., \& Kumar, A. (2010). CFD Approach for Prediction of Efficiency of Francis. IGHM.

[5] Kaunda, C. S., Kimambo, C. Z., \& Nielsen, T. K. (2014). A Technical Discussion on Microhydro Power Technology and Its Turbines. Renewable and Sustainable Energy Reviews, 445-459.

[6] Khare, R., Prasad, V., \& Kumar, S. (2010). CFD Approach for Flow Characteristics of Hydraulic Francis Turbine. International Journal of Engineering Science and Technology Vol. 2(8), 3824-3831.

[7] Kumar, M., Kumar, P., \& Sinha, P. K. (2013). Performance Analysis For Francis Turbine - A Case Study. International Journal of Emerging in Engineering and Development, 377-383.

[8] Wei, Q., \& Choi, Y. D. (2013). The Influence of Guide Vane Opening on The Internal Flow of Francis Turbine. Journal of the Korean Society of Marine Engineering, Vol. 37, No. 3, 274-281.

[9] Panigoro, A., (2013), Beyond 2014 Indonesia Jawara Energi Nabati Dunia Optimalisasi Biodiesel sebagai Solusi Krisis Energi Nasional, Private communication.

[10] Samsul Kamal, Prayitno, (2009), Pengembangan Gorlov Helical Turbine Untuk Pemanfaatan Arus Air Pada Pembangkit Listrik Terapung dengan Apungan Berbentuk Nosel. Research Report, sponsored by HKPSPN, DIKTI 